\title{
Correspondence
}

\section{Diplomate Status: A Matter of Distinction}

To the Editor: I just returned from my state Academy of Family Physicians annual meeting. I noted that time and again the moderators would introduce a speaker as a "diplomat" of the American Board of Family Medicine (ABFM).

In general, a diplomat is an individual who uses skill and tact in dealing with other persons (which physicians certainly do), and this designation usually describes an ambassador appointed to represent a government in its relations and dealings with other governments. To the uninitiated, then, a "diplomat" of the ABFM would have about the same status as a public relations specialist.

A "diplomate," however, as defined by the American Heritage Dictionary of the English Language ${ }^{1}$ is "one who has received a diploma, especially a physician certified as a specialist by a board of examiners." As ABFM diplomates, we demonstrate to our colleagues that we have acquired a broad body of medical knowledge through intensive examination by a national board of senior family medicine specialists. However, do our patients understand what "diplomate" status means? How many of our political leaders appreciate the significance of the title of diplomat?

I submit that the above is much more than a mere matter of semantics and has significance in a much larger context, not only in the delivery of primary health care but also in shaping health care policy. It is entirely possible for non-board-certified family medicine physicians to practice, albeit perhaps with some possible restrictions on issues like insurance participation and medical staff membership. However, the family medicine physician who has pursued and earned diplomate status has demonstrated a dedication to scholarship and expertise in the practice of our discipline. Simply put, diplomate status shows a personal commitment to excellence, and every $\mathrm{ABFM}$ diplomate knows what rigorous requirements his or her fellow diplomates had to meet to earn the title. However, many among the general public and important decision makers in the political leadership very well may not appreciate exactly what ABFM diplomate status entails. By clarifying their understanding of the significance of ABFM diplomate status, I believe that we enhance our credibility in contributing to the discussion of these critical issues.

Considering the current discussions for use of midlevel providers to assume an ever larger role in delivery of primary care ${ }^{2,3}$, if the specialty of Family Medicine is to succeed and thrive in the future it is critical for family medicine physicians to assertively define and defend our role in the health care delivery arena and to enlist allies. Thus, as diplomates of the ABFM, each of us must to educate our patients, the public, and legislators about the unique qualifications of the board-certified family medicine physician as distinguished from other primary health care providers. Midlevel providers play an important role in health care delivery, but this complements-is does not replace-the physician. The knowledge base and skill set developed through medical school and residency training and manifested by attainment of diplomate status set the board-certified family physician apart.

In addition, it is essential for us as family medicine physicians to assume a more active role in advising and shaping the reform of the health care system. Passionate, board-certified family medicine physicians are among the best qualified to help guide this task and ensure the process is focused on patients and centered around primary care. The insight that family physicians are equipped to bring to this process are important to help reduce the administrative and regulatory burdens that add to health care costs and take time away from patient care, reform medical liability laws, reduce the costs of pharmaceutical therapy, and assist in making primary and preventive care and mental health and substance abuse services more readily available to patients.

All family physicians can attest that our discipline is currently buffeted by numerous pressures from within and without: the Medicare Access CHIP Reauthorization Act, with its associated reporting requirements; the impact of noncompliant patients on quality metrics tied to compensation; increases in prior authorization requirements for testing and therapy; negotiations with payers; patient satisfaction scores; increased time spent on administrative and documentation tasks; maintenance of certification; and numerous other forces affecting our daily practices. Coupled with the debate regarding changes in health care delivery and policy, as noted earlier, it is understandable that many family physicians are questioning what the future of our discipline will be.

Several years ago representatives from numerous family medicine organizations convened to define the role of family physicians in order to establish a clear identity for our specialty in the future:

"Family physicians are personal doctors for people of all ages and health conditions. They are a reliable first contact for health concerns and directly address most health care needs. Through enduring partnerships, family physicians help patients prevent, understand, and manage illness, navigate the health system, and set health goals. Family physicians and their staff adapt their care to the unique needs of their patients and communities. They use data to monitor and manage their patient population, and use best science to prioritize services most likely to benefit health. They are ideal leaders of health care systems and partners for public health." 
By adopting the role definition described above as our mission statement and promoting the unique qualifications and perspective that Family Medicine brings to current discussions of primary health care delivery and health care policy, we position our discipline for a leadership role in our national health care system.

Darrell R. Over, MD, MSc, FAAFP

Family Medicine Residency

University of Arkansas for

Medical Sciences (South Central)

Pine Bluff, Arkansas

OverDarrellR@uams.edu

To see this article online, please go to: http://jabfm.org/content/ 31/1/166.full.

\section{References}

1. American heritage dictionary of the English language, 5th ed. Boston, MA: Houghton Mifflin Harcourt; 2016.

2. Liu H, Robbins M, Mehrota A, et al. The impact of using mid-level providers in face-to-face primary care on health care utilization. Med Care 2017;55:12-8.

3. U.S. Department of Health and Human Services, Health Resources and Services Administration, Bureau of Health Workforce, National Center for Health Workforce Analysis. National and regional projections of supply and demand for primary care practitioners: 2013-2025. Rockville (MD): U.S. Department of Health and Human Services; 2016.

4. Phillips RL Jr, Brungardt S, Lesko SE, et al. The future role of the family physician in the United states: a rigorous exercise in definition. Ann Fam Med 2014;12:250-5.

doi: $10.3122 / \mathrm{jabfm} .2018 .01 .170335$

\section{The Numbers Quandary in Family Medicine Obstetrics}

To the Editor: The article "Intention Versus Reality: Family Medicine Residency Graduates' Intention to Practice Obstetrics" by Barreto et $\mathrm{al}^{1}$ illustrates the decline of obstetrics in family medicine. The accompanying editorial by Rayburn ${ }^{2}$ mentions a key barrier to this scope of practice: the lack of standardized pedagogy and supporting research to ensure quality care provided by family medicine obstetric physicians. The question becomes not only whether a sufficient number of family medicine physicians practice obstetrics, but whether our training and standards are rigorous enough to deliver quality care in the face of rising maternal morbidity and mortality. ${ }^{3}$

Regrettably, obstetric training in family medicine is inconsistently measured and inconsistently required. Several studies have concluded that family medicine physicians can deliver quality care, comparable to that provided by obstetricians, but unfortunately these studies are outdated, based in other countries, or limited to a few regional medical centers. ${ }^{4-7}$ The Accreditation Council for Graduate Medical Education recently lowered the number of deliveries that family medicine graduates have to complete in order to graduate from residency. The number of babies that family physicians deliver declines throughout the course of their careers, as does the percentage of physicians who choose to recertify. ${ }^{1,8}$ Fellowship programs vary widely regarding curriculum and graduation requirements. ${ }^{9}$ If obstetric practice is to survive in family medicine, we must consider the forces driving these decisions as we move forward.

Family medicine physicians who provide obstetric care offer a valuable service, especially in underserved rural areas of the United States. To align our outcomes with our intentions, however, we are faced with the option of adopting standardized and studied practices or abandoning obstetrics all together. The resolve of family medicine physicians to continue obstetric practice could be strengthened with specialized tracks in residency programs followed by standardized fellowships with consistent requirements. Rigorous studies of the outcomes of deliveries by family medicine physicians would permit self-evaluation and improvements in training. Insistence on quality and robust preparation must supersede concerns about the numbers of family physicians practicing obstetrics. The number of family medicine obstetricians may continue to decrease, but let them be the few and the proud rather than the many and the untested-our patients deserve nothing less.

Anne Worth, DO

Riverside Methodist Hospital Family Medicine Residency

Columbus, $\mathrm{OH}$ anne.worth@ohiohealth.com

The author thanks to Jennifer Middleton MD, MPH, FAAFP, for providing feedback on and editing this manuscript.

\section{References}

1. Barreto TW, Eden AR, Petterson S, Bazemore AW, Peterson LE. Intention versus reality: fam med residency graduates' intention to practice obstetrics. J Am Board Fam Med 2017;30:405-6.

2. Rayburn $W$. Who will deliver the babies? Identifying and addressing barriers. J Am Board Fam Med 2017;30:402-4.

3. Pregnancy Mortality Surveillance System. Atlanta: Centers for Disease Control and Prevention; 2017. Available from: https://www.cdc.gov/reproductivehealth/maternalinfanthealth/pmss.html. Accessed September 5, 2017.

4. Deutchman ME, Sills D, Connor PD. Perinatal outcomes: a comparison between family physicians and obstetricians. J Am Board Fam Med 1995;8:440-7.

5. Avery DM Jr, Graettinger KR, Waits S, Parton JM. Comparison of delivery procedure rates among obstetriciangynecologist and family physicians practicing obstetrics. Am J Clin Med 2014;10:16-20.

6. Avery DM Jr, Waits S, Parton JM. Comparison of deliveryrelated complications among obstetrician-gynecologists and family physicians practicing obstetrics. Am J Clin Med 2014;10:21-5.

7. Aubrey-Bassler K, Cullen RM, Simms A, et al. Outcomes of deliveries by family physicians or obstetricians: a popula- 